\title{
ESTUDO DA SALINIDADE E SUA RELAÇÃO COM AS FRENTES FRIAS E A PLUVIOSIDADE NO ESTUÁRIO DA LAGOA DOS PATOS
}

\author{
NATALIA PEREIRA, BRUNO RIBEIRO DE CAMPOS, FERNANDO D'INCAO \\ Universidade Federal do Rio Grande - Laboratório de Crustáceos Decápodos, Rio Grande - RS - Brasil. CEP: 96201-900 - Caixa postal: 474. \\ natalialtp@gmail.com
}

\section{RESUMO}

A Lagoa dos Patos possui uma grande interface estuário-oceano que é influenciada diretamente por fatores meteorológicos, tais como: passagens de sistemas frontais e precipitação pluvial. Mudanças nesses regimes acarretam em anomalias no padrão de entrada de água marinha no estuário e na vazão, refletindo na salinidade da região. Essa variação de salinidade influencia no desenvolvimento do camarão-rosa (Farfantepenaeus paulensis). Neste trabalho foram calculadas as médias mensais de salinidade em sete pontos do estuário. Os pontos próximos ao canal que liga o estuário ao oceano possuem maior variabilidade. Os pontos localizados nas regiões mais rasas e abrigados possuem menor variabilidade. Além disso, foi constatado que a passagem de frentes frias pela região influencia no aumento da salinidade no interior do estuário.

PALAVRAS CHAVE: Salinidade, camarão-rosa, Farfantepenaeus paulensis e frentes frias.

\section{ABSTRACT}

Study of salinity and the relationship with cold fronts and rainfall in Patos Laggon Estuary

The Patos Lagoon has a large estuary-ocean interface that is directly influenced by meteorological factors, such as passages of frontal systems and rainfall. Changes in these regimes lead anomalies in the standard input of marine water and flow in the estuary, increasing the salinity. This variation in salinity influences the development of the pink shrimp (Farfantepenaeus paulensis). In this work was calculated the average monthly salinity at seven points in the estuary. Points near the channel connecting the estuary to the ocean have greater variability. Points located in the most shallow and sheltered have less variability. Furthermore, was found that the passage of cold fronts through the region influences the increase of salinity in estuary.

KEYWORDS: salinity, pink shrimp, Farfantepenaeus paulensis, cold fronts.

\section{INTRODUÇÃO}

O estudo da salinidade, definida como a relação de massa dos constituintes dissolvidos na água do mar por massa de solução, está ligado à história da oceanografia química (SEF 2005). Em média, a água do mar de todo o mundo tem uma salinidade de 35 (3,5\% em massa se consideramos apenas os sais dissolvidos, mas a salinidade não tem unidade, o que significa que, para cada litro de água do mar há 35 gramas de sais dissolvidos (a maior parte cloreto de sódio, $\mathrm{NaCl}$ ). A água do mar não tem salinidade uniforme ao redor do globo. A água menos salina do planeta é a do Golfo da Finlândia, no Mar Báltico e o mais salino é o Mar Morto, no Oriente Médio, onde o calor aumenta a taxa de evaporação na superfície e há pouca descarga fluvial (SEF, 2005).

Os ambientes costeiros possuem características diferentes dos oceanos, em relação à salinidade podem ser classificados em liminéticos (salinidade entre 0 e 0,5 ), oligohalinos (salinidade entre 0,5 e 5 ), mesohalinos (salinidade entre 5 e 18), polihalinos (salinidade entre 18 e 30 ), euhalinos (salinidade entre 30 e 40 ) e hiperhalinos (salinidade superior a 40) (Bulger et al., 1998).

Além de ter um papel importante nos movimentos e na mistura das massas de água, devido ao seu efeito na densidade, a salinidade condiciona a fisiologia de invertebrados e vertebrados, como ocorre nos Peneídeos (Bulger et al., 1998).

A Lagoa dos Patos possui uma interface estuário-oceano, que é influenciada diretamente por fatores meteorológicos, tais como: passagens de sistemas frontais e precipitação pluvial. (Moller \& Fernandes 2009). Mudanças nesses regimes acarretam em anomalias no padrão de entrada de água marinha no estuário e na vazão, refletindo na salinidade da região (D'Incao, 1991).

D'Incao (1984) detectou a presença de juvenis de camarão-rosa (Farfantepenaeus paulensis) no estuário da Lagoa dos Patos em salinidade entre $1 \mathrm{e}$ 31. Corleto et al. 1993 analisando o efeito da salinidade no crescimento de $F$. paulensis verificou melhores crescimentos em salinidade 25. Wasielesky (2000), em testes com salinidades baixas, observou que $F$. paulensis mostrou-se bastante tolerante à redução da salinidade, já que a sobrevivência foi de $100 \%$ até a salinidade 3 . Por outro lado, observou que após 48 horas, em salinidade de 0,5 a mortalidade foi de $100 \%$. Resumindo, as salinidades 
letais médias inferiores e superiores variaram entre 1 e 1,48 e entre 54,09 e 49,24 , no período de 24 a 96 horas, respectivamente. Já nos testes que realizou sobre o comportamento osmorregulatório, observou que os juvenis de $F$. paulensis apresentaram altas taxas de sobrevivência entre as salinidades 5 e 40.

Este trabalho tem objetivo estudar as oscilações de salinidade dentro do estuário da Lagoa dos Patos.

\section{MATERIAIS E MÉTODOS}

\section{Área de estudo}

A área de estudo corresponde ao estuário da Lagoa dos Patos, abrangendo uma área da barra do Rio Grande até uma linha imaginária que liga a Ponta da Feitoria $\left(31^{\circ} 41^{\prime} \mathrm{S}, 52^{\circ} 02^{\prime} \mathrm{W}\right)$ a Ponta dos Lençóis $\left(31^{\circ} 48^{\prime} \mathrm{S}, 51^{\circ} 52^{\prime} \mathrm{W}\right)$ (Figura 1).

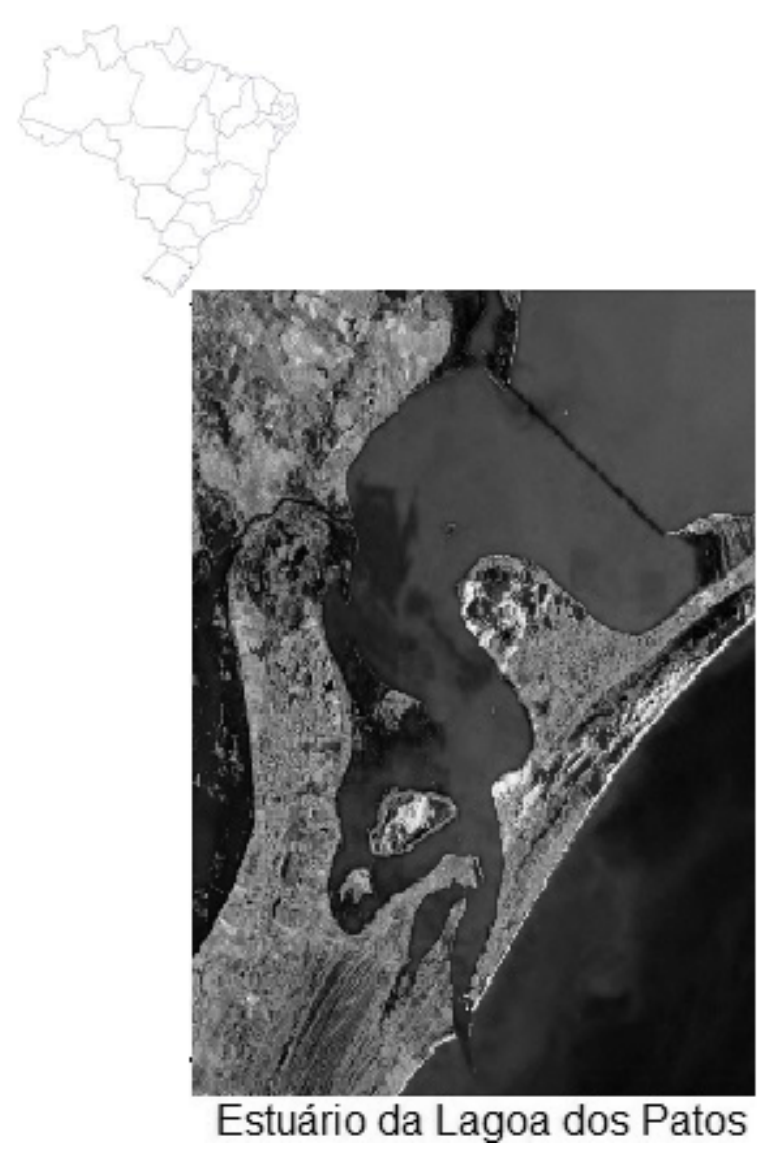

FIGURA 1 - Estuário da Lagoa dos Patos, RS

\section{Dados ambientais e meteorológicos \\ Salinidade}

Foram realizadas coletas diárias de água em sete pontos do estuário: Barra (1), Mangueira (2), Prado (3), Porto Rei (4), Marambaia (5), Fundos (6) e Bandeirinhas (7) (Figura 2). As coletas foram realizadas no período de Fevereiro de 2005 a Dezembro de 2009, com exceção dos pontos Fundos e Porto Rei, onde a coleta começou a ser realizada a partir de Janeiro de 2008. As amostras foram transportadas para o laboratório de Crustáceos
Decápodos do Instituto de Oceanografia da FURG, e aferidas com um refratômetro de refração (uma unidade de salinidade). Gráficos anuais foram traçados. Em alguns gráficos, as linhas estão incompletas devido a problemas com as amostras de água. Por conta de mau tempo ou por falta de transporte até os pontos amostrais, as coletas diárias não foram realizadas. Portanto, em alguns meses obteve-se apenas dez dias de amostragem. Para não 
haver influência nas análises, excluíram-se os meses que não tiveram amostragem completa. Além disso, escolheu-se fazer os gráficos de junho a julho, pois este é o ano biológico do camarão-rosa, já que inicia sua reprodução no final do inverno e início de primavera, desova na primavera e verão, crescimento no verão e outono. (D'Incao 1991).

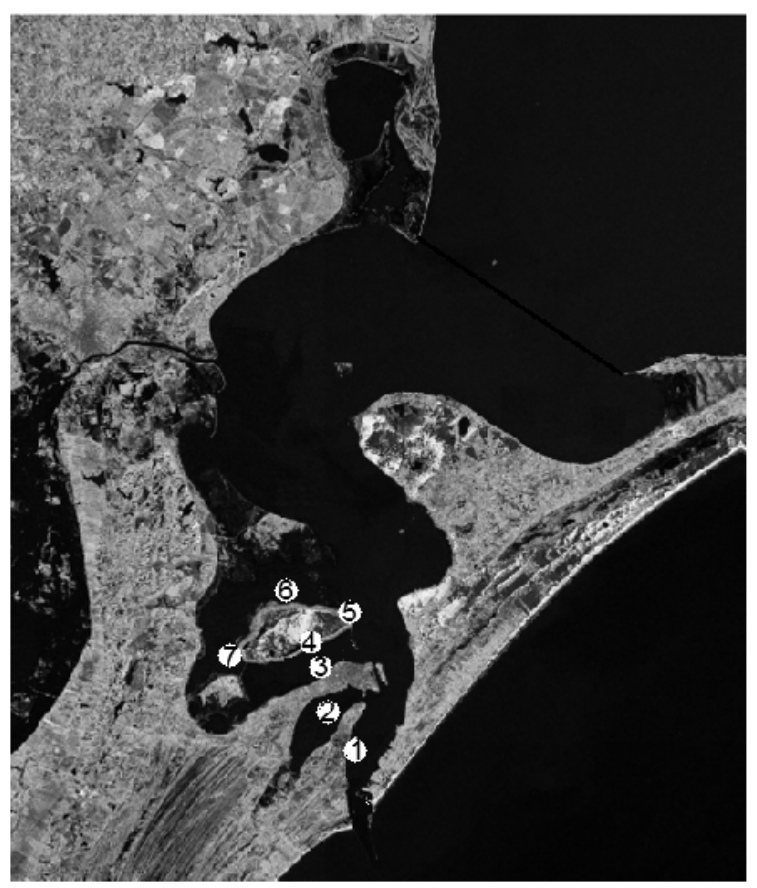

FIGURA 2 - Estuário da Lagoa dos Patos, indicando pontos de coleta de água: 1.Barra, 2.Mangueira, 3.Prado, 4.Porto Rei, 5.Marambaia, 6.Fundos e 7.Bandeirinhas.

\section{Frentes frias}

As Frentes Frias foram analisadas a partir de cartas sinóticas disponibilizadas pelo CPTEC-INPE (Centro de Previsão de Tempo e Estudos Climáticos - Instituto Nacional de Pesquisas Espaciais). Estas cartas são disponibilizadas três vezes ao dia $(00,12 \mathrm{e}$ 18 UTC) no site http://www.cptec.inpe.br, viabilizando o acompanhamento da passagem das frentes pelo $\mathrm{RS}$, bem como sua intensidade.

As frentes frias clássicas, ou apenas os cavados baroclínicos (frentes menos intensas), foram acompanhados por suas características gerais, como gradiente de temperatura do ar, gradiente de temperatura do ponto de orvalho, inversão do vento de norte/noroeste para sudeste/sul e aumento da pressão atmosférica. A partir daí desenvolveu-se uma classificação numérica para a intensidade das frentes que atingem a nossa região, para que elas pudessem ser inseridas nos gráficos. As frentes frias foram classificadas como: inexistente (0), fraca (10), moderada (20) e intensa (30). Essa classificação de intensidade foi baseada de acordo com o grau de variação dos gradientes e na posição do sistema nas cartas sinóticas de superfície, pois quanto mais inclinado o sistema, mais baroclínico ele é, portanto causa maiores mudanças no tempo sobre a região por onde a frente passa.

\section{Análise dos dados}

Primeiramente foram calculadas as médias mensais de salinidade de cada ponto amostral para cada um dos anos estudados e seus intervalos de confiança. O segundo método utilizado foi a Análise de Agrupamento (AA) (Everitt 1974 e Gong \& Richman 1995). A análise de agrupamento e os Dendrogramas foram feitos através do software PAST (Hammer et al., 2003), e o coeficiente de similaridade 
utilizado foi o de Bray-curtis.

A análise da relação entre a passagem dos sistemas frontais e o aumento da salinidade no interior do estuário foi realizada através do cálculo de porcentagem (\%). Foram contabilizados todos os sistemas frontais frios que passaram pela região. Eles foram somados de acordo com suas intensidades $(0$, 10, 20 ou 30), conforme descrito anteriormente. Após essa contabilização, contaram-se quantos desses sistemas resultaram no aumento na salinidade no interior do estuário. Essa porcentagem foi expressa em gráfico.

Foram criados dendrogramas anuais, para visualizar a similaridade dos pontos de coleta, em relação à salinidade, sob o efeito dos mesmos fatores físicos, químicos e meteorológicos que atuaram sobre o estuário da Lagoa dos Patos. A escala vertical indica o nível de similaridade; quanto mais elevado o índice, mais homogêneos os locais agrupados.

\section{RESULTADOS}

Abaixo os gráficos anuais de salinidade.

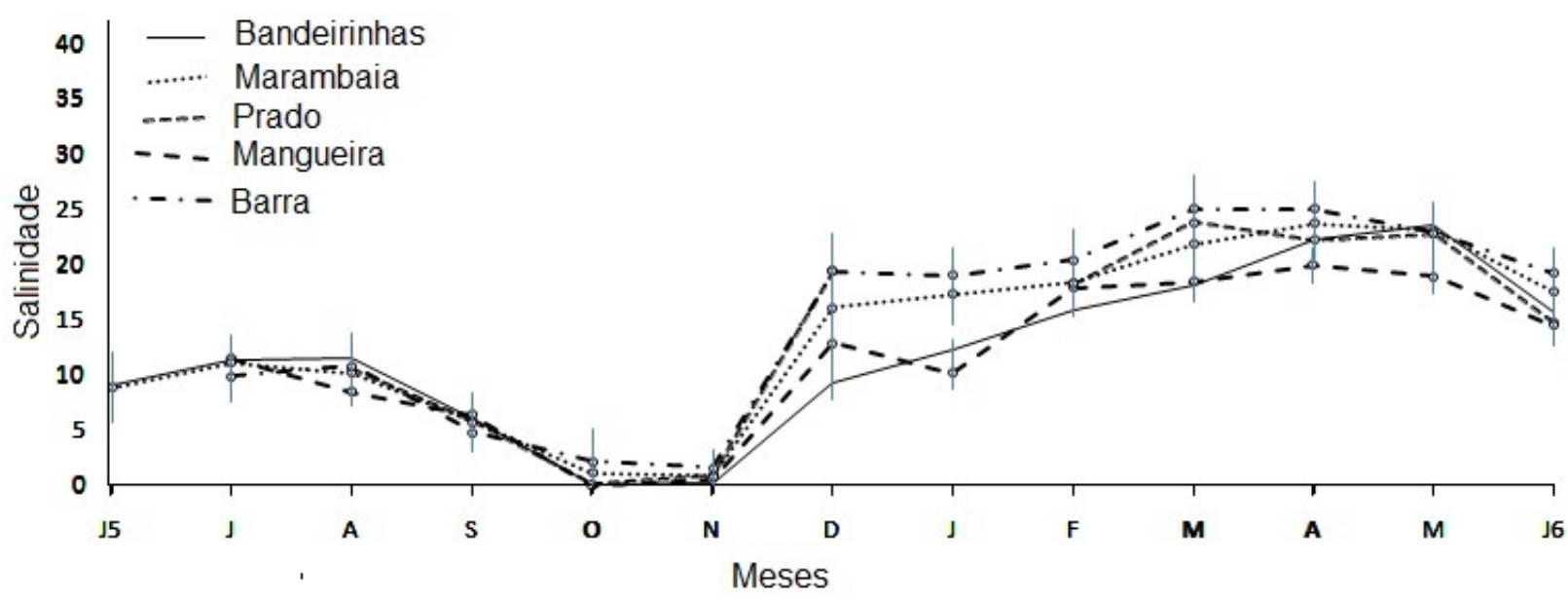

FIGURA 3 - Variação da salinidade média mensal nos ponto de coleta: Bandeirinhas, Marambaia, Prado, Mangueira e Barra, no período entre junho de 2005 e junho de 2006.

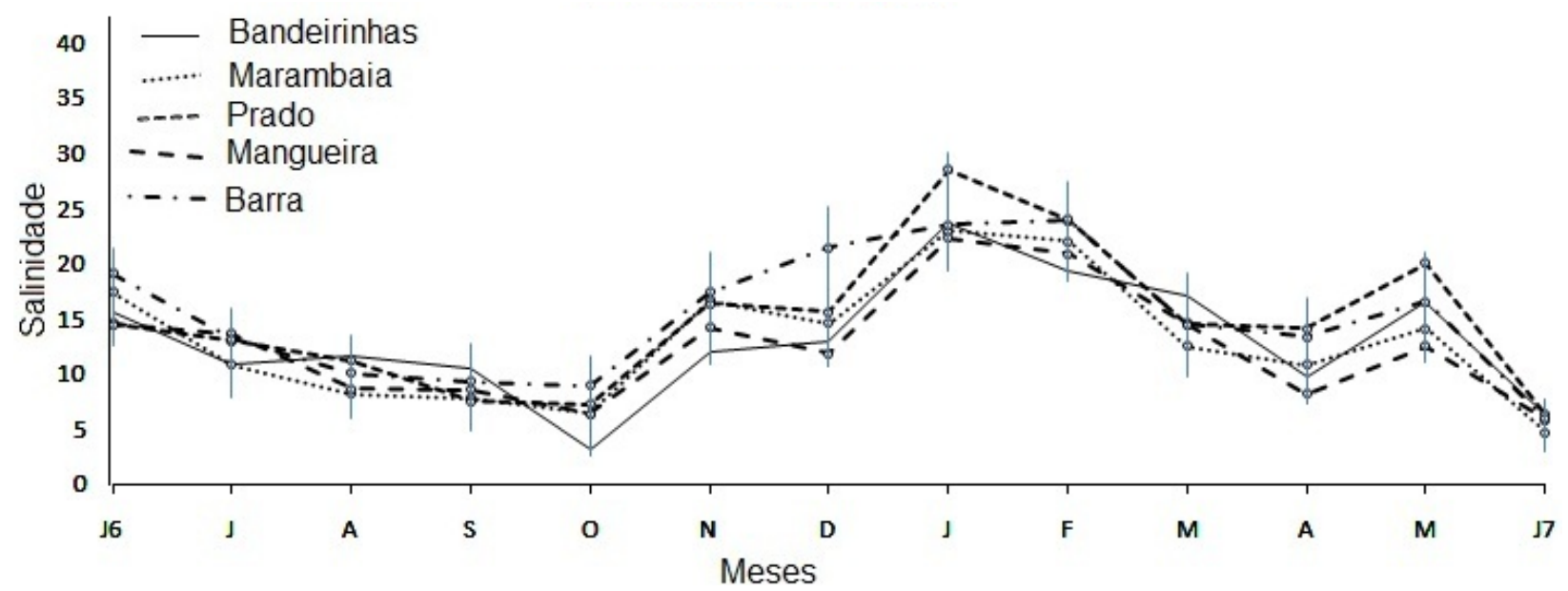

FIGURA 4 - Variação da salinidade média mensal nos ponto de coleta: Bandeirinhas, Marambaia, Prado, Mangueira e Barra, no período entre junho de 2006 e junho de 2007. 


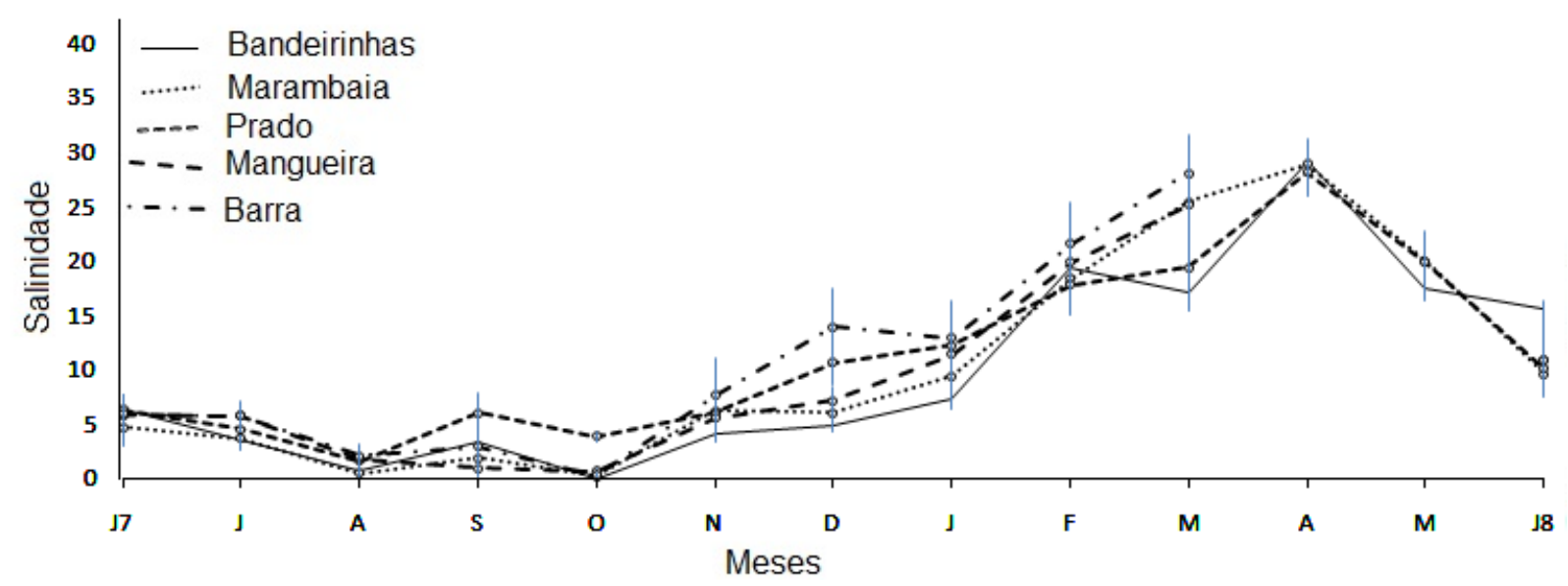

FIGURA 5 - Variação da salinidade média mensal nos ponto de coleta: Bandeirinhas, Marambaia, Prado, Mangueira e Barra, no período entre junho de 2007 e junho de 2008.

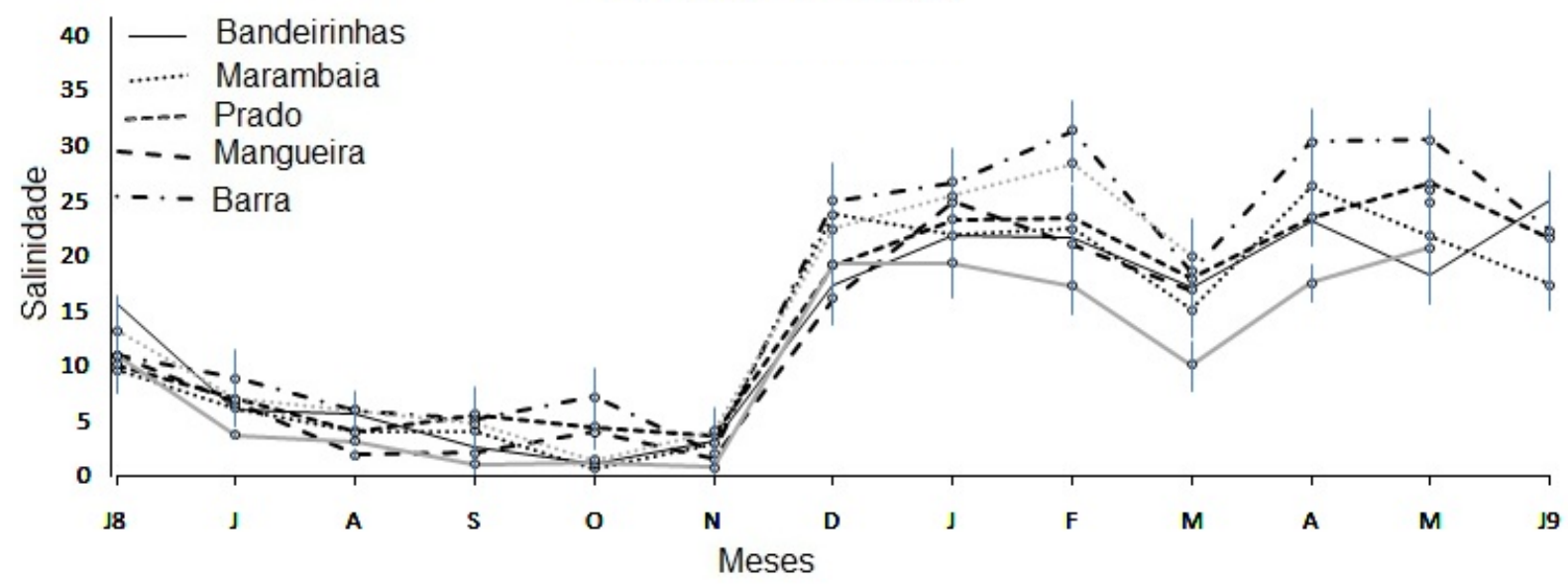

FIGURA 6 - Variação da salinidade média mensal nos ponto de coleta: Bandeirinhas, Marambaia, Prado, Mangueira, Barra, Fundos e Porto Rei, no período entre junho de 2008 e junho de 2009.

$\mathrm{Na}$ figura 2 observa-se que a salinidade manteve-se baixa entre 0 e 10 de junho a novembro de 2005. A partir de dezembro de começou a aumentar, permanecendo entre 15 e 25 , na maioria dos pontos, até junho de 2006.

Nos pontos Mangueira e Bandeirinhas esses valores foram atingidos a partir de fevereiro de 2006.

A partir de junho de 2005, a salinidade permaneceu baixa pela pouca influência dos sistemas frontais $(45 \%)$ que atuaram no período.

Já no primeiro semestre de 2006, a salinidade no estuário permaneceu alta, pois a passagem dos sistemas frontais foi mais significativa (90\%).

A salinidade do estuário, em junho de 2006, ficou entre 15 e 19. A partir de julho de 2006 começou a diminuir, tendo seus menores valores registrados no mês de outubro de 2006 (valores entre 4 e 10). Em nenhum ponto a salinidade foi zero neste período.
Isso ocorreu pela grande influência da passagem dos sistemas frontais deste ano. A partir de novembro de 2006, a salinidade, em todos os pontos, começou a aumentar, permanecendo em torno de $15 \mathrm{em}$ novembro e dezembro e 30 em janeiro.

Já na figura 4 observa-se que a partir de fevereiro de 2007, a salinidade começou a diminuir gradativamente, em torno de 5 a cada mês.

Durante o período entre junho e novembro de 2007 (Figura 5) a salinidade em todos os pontos permaneceu próxima á zero. A partir de dezembro de 2007 começou a aumentar, mas não ultrapassou o valor 15. Apenas em fevereiro de 2008 a salinidade aumentou mais, ficando próxima de 20 . Em março ficou próxima dos 30 , no ponto Barra, e em abril em torno de 30 , em todos os outros pontos.

A salinidade no segundo semestre de 2007 ficou baixa pela pequena influência dos sistemas 
frontais. Apenas 50\% deles contribuíram para a entrada de água salgada no estuário.

Nas figuras 4 e 5 observa-se que a salinidade manteve-se baixa entre 0 e 15 nos meses de junho a novembro de 2008. A partir de dezembro de 2009 começou a aumentar, permanecendo, em média, entre 20 e 30 até junho de 2009.

O segundo semestre de 2008 seguiu o mesmo padrão de 2007. Por conta da pequena influência dos sistemas frontais, a salinidade permaneceu muito baixa.

$\mathrm{Na}$ figura 6 observa-se que o primeiro semestre de 2009 seguiu o padrão de 2006. A passagem de sistemas frontais bem fortes resultou na entrada de muita água salgada no estuário.

A figura 7 indica, ainda, a diferença anual da influência das passagens das frentes frias no aumento da salinidade no estuário.

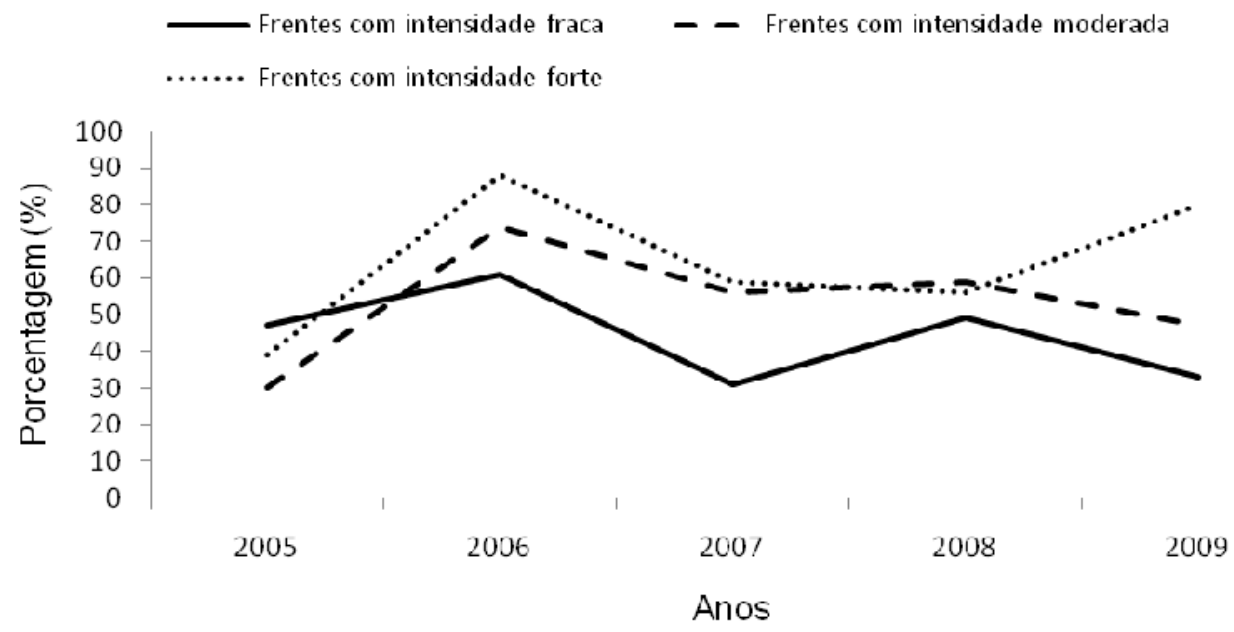

FIGURA 7 - Influência da passagem de frentes frias, de diferentes intensidades, expressa em porcentagens, no aumento da salinidade no estuário da Lagoa dos Patos, nos anos de 2005, 2006, 2007, 2008 e 2009.

Em 2005, as frentes frias tiveram uma influência de $40 \%$ no aumento da salinidade no estuário. Em 2006, este índice aumentou para 70\%. Em 2007 e 2008, o índice foi de $50 \%$ e em 2009 foi de $60 \%$.
As Figuras 8, 9, 10, 11 e 12 mostram os resultados finais da análise de agrupamento utilizando os dendrogramas.

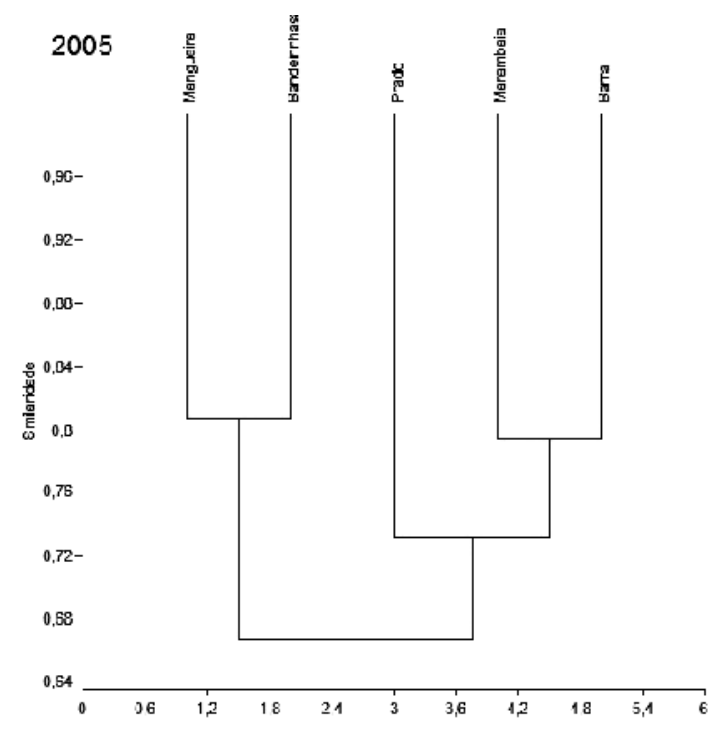

FIGURA 8 - Dendrograma do agrupamento, obtido pelo método de similaridade (coeficiente de Bray-Curtis), dos dados de salinidade dos cinco pontos de coleta, Mangueira, Marambaia, Bandeirinhas, Prado e Barra, no ano de 2005. 


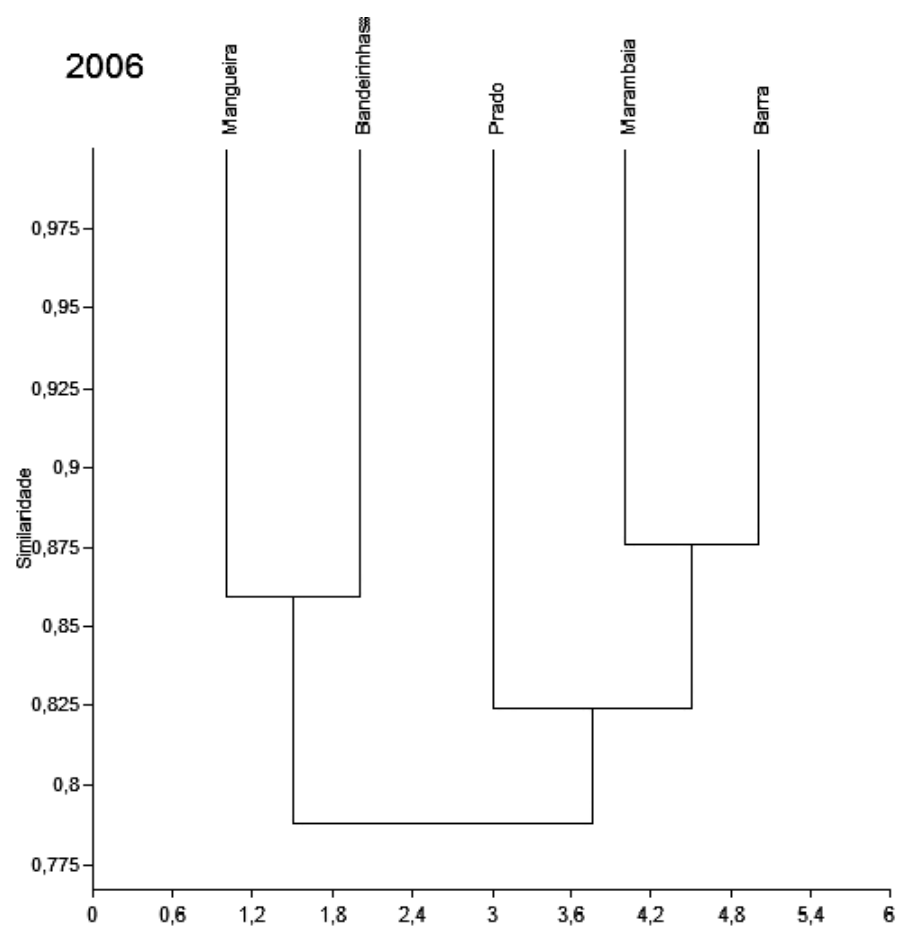

FIGURA 9 - Dendrograma do agrupamento, obtido pelo método de similaridade (coeficiente de Bray-Curtis), dos dados de salinidade dos cinco pontos de coleta, Mangueira, Marambaia, Bandeirinhas, Prado e Barra, no ano de 2006.

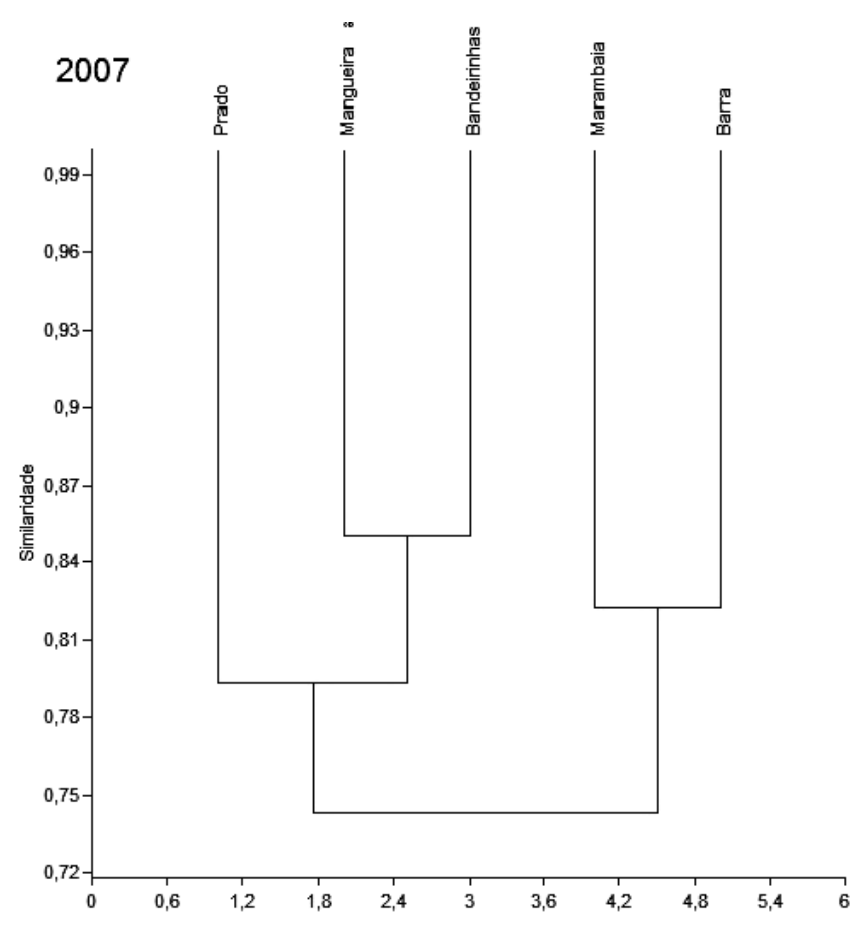

FIGURA 10 - Dendrograma do agrupamento, obtido pelo método de similaridade (coeficiente de Bray-Curtis), dos dados de salinidade dos cinco pontos de coleta, Mangueira, Marambaia, Bandeirinhas, Prado e Barra, no ano de 2007. 


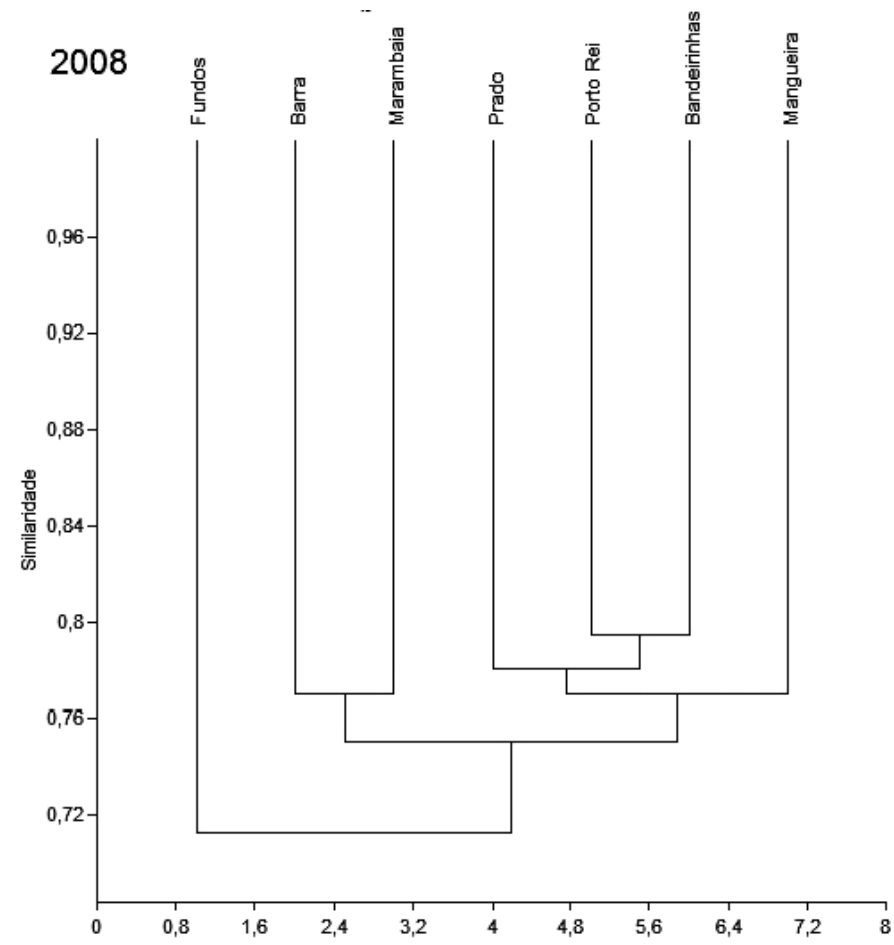

FIGURA 11 - Dendrograma do agrupamento, obtido pelo método de similaridade (coeficiente de Bray-Curtis), dos dados de salinidade dos sete pontos de coleta, Mangueira, Marambaia, Bandeirinhas, Prado, Barra, Fundos e Porto Rei, no ano de 2008.

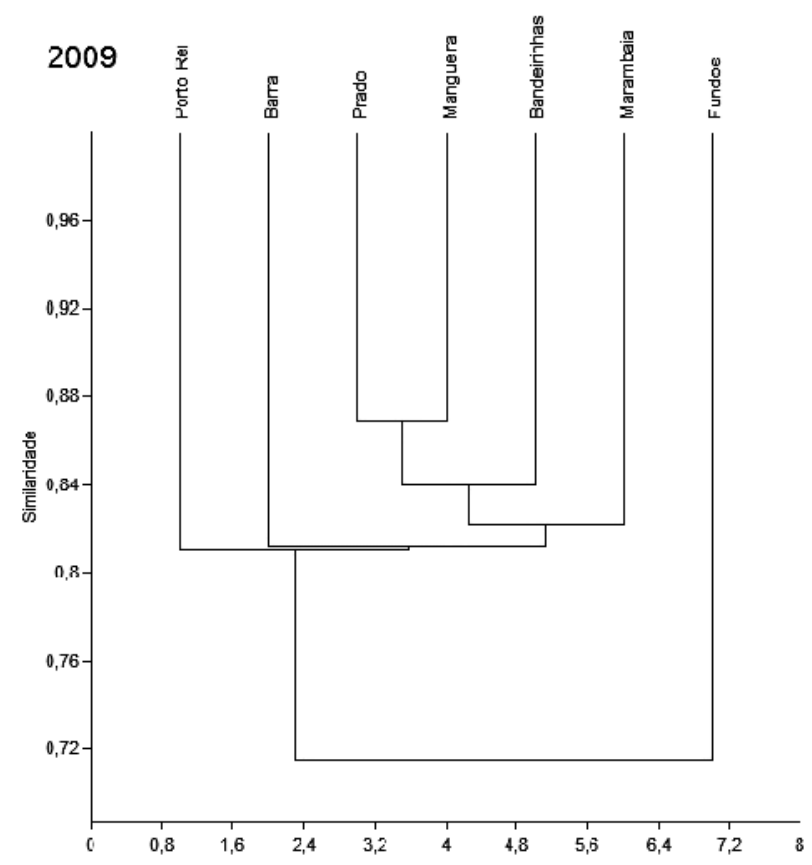

FIGURA 12 - Dendrograma do agrupamento, obtido pelo método de similaridade (coeficiente de Bray-Curtis), dos dados de salinidade dos sete pontos de coleta, Mangueira, Marambaia, Bandeirinhas, Prado, Barra, Fundos e Porto Rei, no ano de 2009.

Nas figuras 8, 9 e 10 observamos um padrão no comportamento da salinidade nos pontos amostrais. Nesses três anos, os pontos Barra e Marambaia e Bandeirinhas e Mangueira mostraram-se mais parecidos. O local que mais se diferenciou foi o Prado. $\mathrm{Na}$ figura 11, referente a 2008, Barra e Marambaia novamente se assemelham. Já os pontos Mangueira e Bandeirinhas se assemelharam com os 
pontos Prado e Porto Rei, respectivamente. O ponto Fundos foi o que mais se diferenciou de todos.

$\mathrm{Na}$ figura 12, referente a 2009, a salinidade comportou-se de maneira diferente dos outros anos. Os pontos que mais se assemelharam foi Prado e Mangueira, que posteriormente assemelharam-se com Bandeirinhas, Marambaia, Barra e porto Rei.

\section{DISCUSSÃo}

No período entre junho de 2005 e novembro de 2005 , todos os pontos amostrais se comportaram, em relação à salinidade, da mesma maneira, inclusive os valores das médias mensais foram muito parecidos. Em junho, julho e agosto a salinidade esteve entre $8 \mathrm{e}$ 11. A partir de setembro, a salinidade começou a diminuir, chegando à zero em outubro e novembro. Esse fato ocorreu por causa da pequena influência das frentes frias na região; cada vez que um sistema frontal frio passa pela região, faz com que o vento mude para o quadrante sul, permitindo a entrada de água salgada no estuário (Pereira et al 2010). Como em 2005, apenas $45 \%$ das frentes causaram um aumento na salinidade, ela manteve-se baixa por este longo período. A salinidade no estuário começou a aumentar no mês de dezembro, porém não passou de 20 durante três meses (dezembro, janeiro e fevereiro) e esteve próxima de 25 apenas na Barra em abril e maio. Esse dado nos permite inferir que as pós-larvas de camarão-rosa neste ano, começaram a entrar no estuário em dezembro, discordando com Barcellos (1968a) que afirmou que a entrada de pós-larvas ocorre no final de setembro e mais acentuadamente entre outubro e novembro e Calazans (1978) que apontou que a penetração de larvas teria início em agosto. No entanto, essa entrada de água tardia e em pouca quantidade no estuário, não permitiu que se obtivesse uma safra bastante elevada nesse ano e nem um crescimento satisfatório dos indivíduos. A safra de 2006 foi de $2274 \mathrm{t}$ (toneladas) (IBAMA, 2007), com pesca no período de fevereiro a maio.

As flutuações das salinidades médias mensais, no período entre junho de 2006 e junho de 2007, também não foram muito diferentes em todos os pontos estudados. No entanto, neste ano, os valores das salinidades não estiveram tão baixos como no ano anterior (2005). Em 2006, mudou-se o padrão
Novamente, o ponto Fundos foi o mais discrepante.

Dos cinco anos estudados, o período de junho de 2008 a junho de 2009 foi o que indicou maiores diferenças entre os pontos estudados. Isso pode ser explicado, em parte, pelo fato de terem sido acrescentados dois pontos na análise, Fundos e Porto Rei.

dos sistemas frontais na região. As frentes estavam mais fortes e mantinham a presença do vento sul por vários dias, ao longo do ano, fazendo com que a salinidade não chegasse a zero em nenhum mês.

Entre junho e setembro de 2006, a salinidade média oscilou entre 9 e 18, manteve-se em torno de 7 em outubro e começou a aumentar em novembro, permanecendo alta até maio de 2007. Isso permitiu a entrada de pós-larvas já em novembro neste ano, corroborando com Barcellos (1968a). Isso resultou em uma safra de camarão-rosa bastante satisfatória para os pescadores da região. A safra de 2007 foi de $3687 \mathrm{t}$ (toneladas) (IBAMA, 2008) e também houve pesca de fevereiro a maio.

O período entre junho de 2007 e junho de 2008 corresponde a um período de La Niña, que por sua vez resulta em índices pluviométricos abaixo da normal climatológica para a região (Grimm et al., 2000), consequentemente, os valores mensais de salinidade, em todos os pontos, estiveram elevados nesses meses. Inferiu-se que a entrada de pós-larvas começou a ocorrer em novembro; no entanto, a safra de 2008 só iniciou em março e não foi tão satisfatória para os pescadores. A safra foi de $1741 \mathrm{t}$ (toneladas) (IBAMA, 2009). Este cenário é esperado uma vez que o sucesso das safras anuais de camarão-rosa no estuário não é dependente, apenas, de fatores meteorológicos. Uma explicação factível seria a não disponibilidade de pós-larvas no oceano nos meses nos quais a água salgada começou a entrar nos estuário, porém isso ainda precisa ser investigado.

O fenômeno La Niña, novamente esteve presente neste período, ou seja, ocorreram duas La Niñas seguidas, uma com início em junho de 2007 até maio de 2008 e a segunda com início em agosto de 2008 até março de 2009. Os índices pluviométricos de 2008 e 2009, na Lagoa dos Patos estiveram abaixo da média 
climatológica, e as frentes frias foram intensas, o que favoreceu o aporte de água salina no estuário.

A salinidade começou a aumentar no mês de dezembro de 2008, de forma semelhante a dezembro de 2005, porém com médias mensais maiores. Diante disso, pode-se dizer que a quantidade de água salina que entrou no estuário foi maior, conseqüentemente, o número de pós-larvas transportadas para o interior do estuário também foi maior. Essa constatação pode ser confirmada pelo sucesso da safra de 2009, que embora tenha sido uma safra curta, foi considerada pelos pescadores da região, bastante satisfatória. Ainda não está disponível o valor anual da safra.

Todos os pontos estudados possuem uma variação média de salinidade semelhante, pois embora exista uma dinâmica de circulação particular em cada ponto do estuário da Lagoa dos Patos (Moller et al., 2009), as regiões são muito próximas e a circulação superficial da água é regida pela mesma variável, que é o vento (Moller et al., 2009). No entanto, encontramos uma maior relação entre os pontos Barra e Marambaia, o que já era esperado, uma vez que esses dois pontos posicionam-se próximos ao canal de acesso ao oceano e não dentro de algum saco, que dependem de um aporte maior de água salina no estuário e vento do quadrante leste para transportar esta água até essas regiões. Desta mesma forma, para a água salina sair desses pontos mais abrigados, o índice pluviométrico na Lagoa dos Patos precisa ser bem alto, ou seja, para que a salinidade dentro dos sacos, que são locais mais rasos e mais abrigados, flutue, as mudanças nos fatores físicos e dinâmicos que regem o fluxo de água têm que ser mais acentuadas, diferentemente dos pontos Marambaia e Barra, onde qualquer alteração no regime de ventos altera a salinidade. Esse fator explica uma maior quantidade de pós-larvas encontrada nos baixios (sacos). Esses locais, além de ser mais abrigados e protegidos de predadores, a salinidade oscilam menos, portanto as pós-larvas não precisam de um gasto energético muito grande para manter sua osmorregulação, resguardando-se para a alimentação e seu desenvolvimento.

\section{AGRADECIMENTOS}

Ao Conselho Nacional de Pesquisa e Desenvolvimento (CNPq) pela concessão da bolsa de mestrado.

\section{REFERÊNCIAS}

BARCELLOS, BN. 1968a. Resultados preliminares da pesca exploratória de camarões na costa do Rio Grande do Sul. I Bol. Inform. Ind. Pesca., 1: 1-19.

BULGER, AJ, BP HAYDEN, ME MONACO, DM NELSON \& MG MCCORMICK-RAY. 1998. Biologically-Based Estuarine salinity zones derived from a Multivariate analisys. Estuaries. 16: 311-322.

CALAZANS, DK. 1978. Penetração das post-larvas do "camarãorosa" (Penaeus paulensis) no estuário da Lagoa dos Patos, RS, Brasil. V Simpósio Latinoamericano sobre Oceanografia Biológica. 125-126 (Resumos).

CORLETO, F, RO CAVALLI \& MA MARCHIORI. 1993. Crescimento de pós-larvas de Penaeus paulensis (PÉREZ-FARFANTE, 1967) em diferentes salinidades. IV Encontro Riograndense de Técnicos em Aquicultura. 13-23.

D'INCAO, F. 1984. Estudo sobre o crescimento de Penaeus (Farfantepenaeus) paulensis Pérez-Farfante, 1967 da Lagoa dos Patos, RS, Brasil. (Decapoda, Penaeidae). Revista Atlântica. 3: 57-66.

D'INCAO, F. 1991. Pesca e biologia de Penaeus paulensis na Lagoa dos Patos, RS. Revista Atlântica. 13: 159-169.

EVERITT, B. 1974. Cluster Analysis. London, Heinemann Books. $135 p$.

GONG, X \& MB RICHMAN. 1995. On the Application of Cluster Analysis to Growing Season Precipitation Data in North America East of the Rockies. Journal of Climate. 8: 897-2135.

HAMMER, O, DTA HARPER \& PD RYAN. 2003. PAST Palaeontological Statistics, ver. 1.12. Disponível em: <http://www.folk.uio.no/ohammer/past>. Acesso em: 31/07/2009.

IBAMA, 2007. Desembarques de pescados no Rio Grande do Sul, 2006. Projeto Estatística Pesqueira. Rio Grande, IBAMA/CEPERG. 45p.

IBAMA, 2008. Desembarques de pescados no Rio Grande do Sul, 2007. Projeto Estatística Pesqueira. Rio Grande, IBAMA/CEPERG, 45p.

IBAMA, 2009. Desembarques de pescados no Rio Grande do Sul, 2008. Projeto Estatística Pesqueira. Rio Grande, IBAMA/CEPERG, 45p. SEF, MEC. 2005. Geografia: Ensino Fundamental e Médio: O mar no espaço geográfico brasileiro. Brasília. 304p.

WASIELESKY, WJ. 2000. Cultivo de juvenis do camarão-rosa Farfantepenaeus paulensis (Decapoda, Penaeidae) no estuário da Lagoa dos Patos: efeitos dos parâmetros ambientais. Tese de doutorado. Fundação Universidade Federal de Rio Grande, Rio Grande, RS. 199p. 